\title{
Article \\ Enriching Mobile Learning Software with Interactive Activities and Motivational Feedback for Advancing Users' High-Level Cognitive Skills
}

\author{
Christos Troussas*(D), Akrivi Krouska (D) and Cleo Sgouropoulou
}

check for

updates

Citation: Troussas, C.; Krouska, A.; Sgouropoulou, C. Enriching Mobile Learning Software with Interactive Activities and Motivational Feedback for Advancing Users' High-Level Cognitive Skills. Computers 2022, 11, 18. https://doi.org/10.3390/ computers11020018

Academic Editors: Antonio Sarasa Cabezuelo and Covadonga Rodrigo San Juan

Received: 1 December 2021 Accepted: 24 January 2022 Published: 25 January 2022

Publisher's Note: MDPI stays neutral with regard to jurisdictional claims in published maps and institutional affiliations.

Copyright: (c) 2022 by the authors. Licensee MDPI, Basel, Switzerland. This article is an open access article distributed under the terms and conditions of the Creative Commons Attribution (CC BY) license (https:/ / creativecommons.org/licenses/by/ $4.0 /)$.
Department of Informatics and Computer Engineering, University of West Attica, 12243 Athens, Greece; akrouska@uniwa.gr (A.K.); csgouro@uniwa.gr (C.S.)

* Correspondence: ctrouss@uniwa.gr

\begin{abstract}
Mobile learning is a promising form of digital education to access learning content through modern handheld devices. Through mobile learning, students can learn using smartphones, connected to the Internet, without having restrictions posed by time and place. However, such environments should be enriched with sophisticated techniques so that the learners can achieve their learning goals and have an optimized learning experience. To this direction, in this paper, presents a mobile learning software which delivers interactive activities and motivational feedback to learners with the aim of advancing their higher level cognitive skills. In more detail, the mobile application employs two theories, namely Bloom's taxonomy and the taxonomy of intrinsic motivations by Malone and Lepper. Bloom's taxonomy is used for the design of interactive activities that belong to varying levels of complexity, i.e., remembering, understanding, applying, analyzing, evaluating, and creating. Concerning motivational feedback, the taxonomy of intrinsic motivations by Malone and Lepper is used, which identifies four major factors, namely challenge, curiosity, control, and fantasy, and renders the learning environment intrinsically motivating. As a testbed for our research, the presented mobile learning system was designed for the teaching of a primary school course; however, the incorporated taxonomies could be adapted to the tutoring of any course. The mobile application was evaluated by school students with very promising results.
\end{abstract}

Keywords: Bloom's taxonomy; learning activities; mobile learning; Malone and Lepper's taxonomy; motivational feedback; taxonomy of intrinsic motivations

\section{Introduction}

Recently, significant interest has been placed on the inclusion of digital technologies in education. The rise of information and communication technology has brought new and considerable changes in many research areas, and particularly, in education. For example, several expert e-learning systems have been developed to help students advance their knowledge [1-3].

The modernization of education is now imperative and requires the use of digital tools [4], which has become profound especially during the COVID-19 pandemic. In this way, multidimensional education and cultivation, constant cognitive vigilance, and development of critical thinking can be further promoted. Students can also adapt to the continuous flow of information. Therefore, the ever-increasing need for digital education, overcoming the barriers posed by space and time, has led to mobile learning (m-learning), which supports learning in multiple contexts using personal electronic devices [5].

Learning through mobile phones is beneficial as it allows learners to learn from wherever they are, always according to their individual needs and preferences. It is a hot topic in the relevant scientific literature, as it promotes learning in an entertaining way and encourages student motivation, therefore, increasing their involvement in the educational process [6]. Therefore, it can improve the learning process and student participation. 
On the one hand, learning activities, incorporated in mobile learning environments, are pedagogically useful [7] but they should be designed properly to provide best results in learners' knowledge advancement. On the other hand, motivating learners can be a powerful tool for advancing users' high-level cognitive skills [8].

In the related scientific literature, there have been several efforts that explore the delivery of learning activities and motivational messages to users. In particular, the topic of learning activities has been examined in several works [7,9-14]. In most of these works, the authors have used learning management systems and they have focused on providing example-based or collaborative learning activities. Moreover, the delivery of motivational messages has been researched in many works [8,15-20]. In most of these works, the authors have mainly focused on the motivation types of learners. The novelty of our approach is, firstly, that the user interface is a mobile learning environment which requires greater focus both on the design of learning activities and on the way of motivational messages delivery, due to its capacity. Secondly, another novelty is the blending of two taxonomies, namely Bloom's taxonomy [21] and the taxonomy of intrinsic motivations by Malone and Lepper [22], to optimize the delivery of learning activities and motivational messages to users. Analyzing the presented literature, it needs to be noted that different theories and/or models have not been sufficiently employed in combination yet to support the process of mobile learning. However, as stated in a recent review work [23], incorporating such techniques into a learning environment can have important pedagogical potential and offer learner-centered education in the context of adaptive and personalized learning.

Regarding the instructional system design, it involves the creation of learning experiences in ways that leads to the acquisition and application of cognitive and thinking skills (https:/ / www.td.org/talent-development-glossary-terms/what-is-instructionaldesign, accessed on 30 November 2021). In light of the foregoing, learning solutions that have been adopted in instructional design have involved the incorporation of theories and/or taxonomies for a better eLearning plan, and the employment of instructional design models (e.g., ADDIE, Merrill's First Principles of Instruction, Dick and Carey Model, Kemp Design Model, Agile and iterative approaches, etc.) [24]. There have been several research works that deal with the field of instructional design modeling [25-31]. In this paper, the aim is to adopt an adequate instructional design in mobile learning through focusing on the incorporation of two taxonomies and employing agile modeling.

In view of the above, this paper presents a novel approach for the provision of interactive learning activities and motivational feedback to learners in a mobile environment. To preserve the pedagogical affordance of the application, two taxonomies have been employed, as mentioned above. Bloom's taxonomy is used for the design of interactive activities belonging to varying levels of complexity, i.e., remembering, understanding, applying, analyzing, evaluating, and creating. The taxonomy of intrinsic motivations by Malone and Lepper is used to identifying four major factors, namely challenge, curiosity, control, and fantasy. As a testbed for our research, a mobile learning software is developed for a primary school course. The mobile software is evaluated in a public primary school and the results are very encouraging, as presented in Section 4.

The remainder of the paper is organized as follows: In Section 2, the method and procedures of this research is presented as well as the logical architecture of the application is explained; in Section 3, the application's modules are described, namely interactive learning activity delivery using Bloom's taxonomy and motivational feedback delivery using Malone and Leeper's taxonomy; the evaluation of the mobile application is showed in Section 4; finally, in Section 5, the conclusions are drawn and future research plans are presented.

\section{Methods and Procedures}

This section presents important aspects of this research. The purpose of the research is to improve online learning environments by enriching mobile learning applications with effective cognitive theories. The blending of different theories (Figure 1), namely 
Bloom's and Malone and Leeper's taxonomies, serves to further enhance the delivery of learning activities and motivational feedback, respectively; these two learning ingredients can booster the personalized experience of learners.

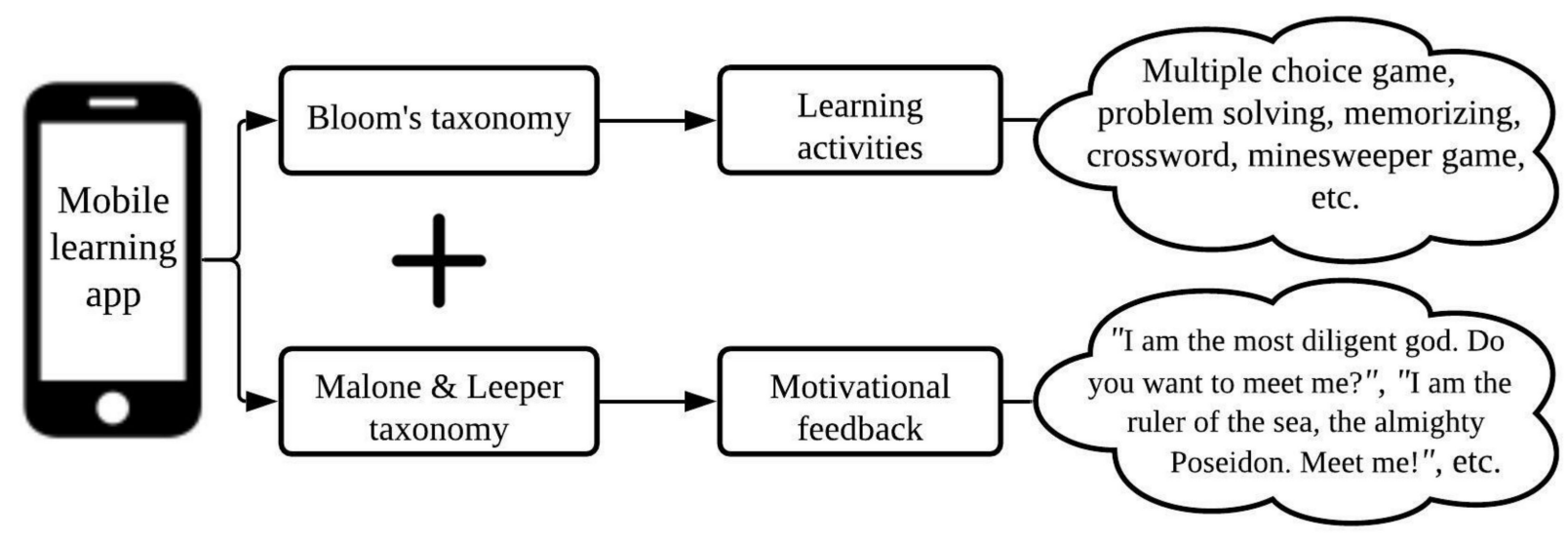

Figure 1. Logical architecture of the mobile learning application.

The steps that we followed in this research included the literature review, the design and implementation of the mobile application, the utilization of the application by school students, and the evaluation. The mobile learning software was developed for tutoring of a third-year primary school course in History, specifically, the chapter on Greek Mythology. The application was used by students, and was evaluated using techniques, such as interviews and a Likert scale questionnaire survey which was based on an established framework.

\section{Modules Analysis and Presentation of the Application}

In this section, the application modules are described, namely the modules on interactive learning activities delivery and motivational feedback delivery. In addition, an overview of the application is provided.

\subsection{Interactive Learning Activities Delivery}

The delivery of the interactive learning activities to learners is based on Bloom's taxonomy [21] (Figure 2). According to Bloom's taxonomy, the educational goals are ranked in a hierarchical form with remembering being the first tier (Figure 3a).

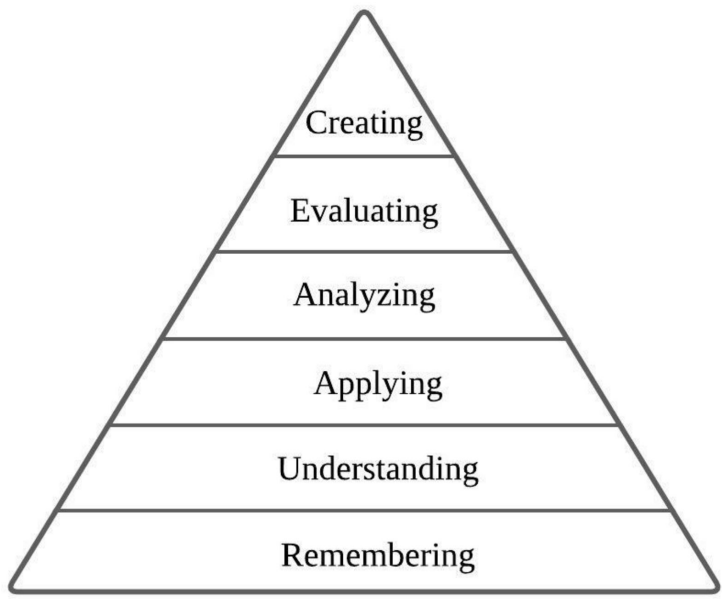

Figure 2. Bloom's taxonomy levels. 


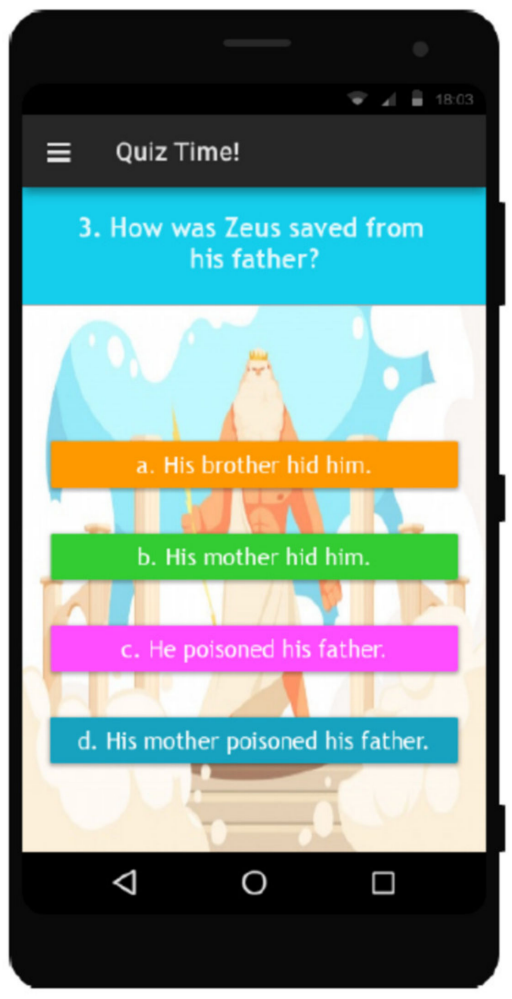

(a)

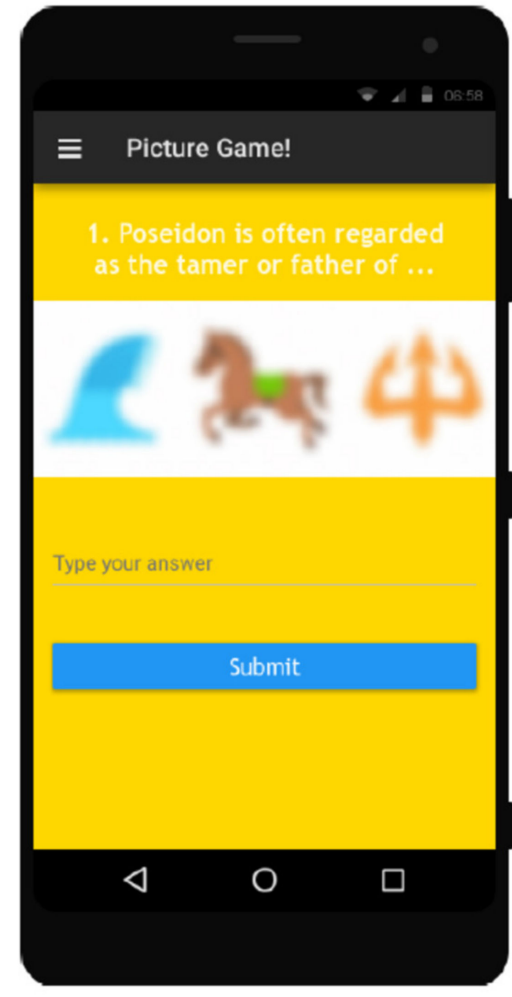

(b)

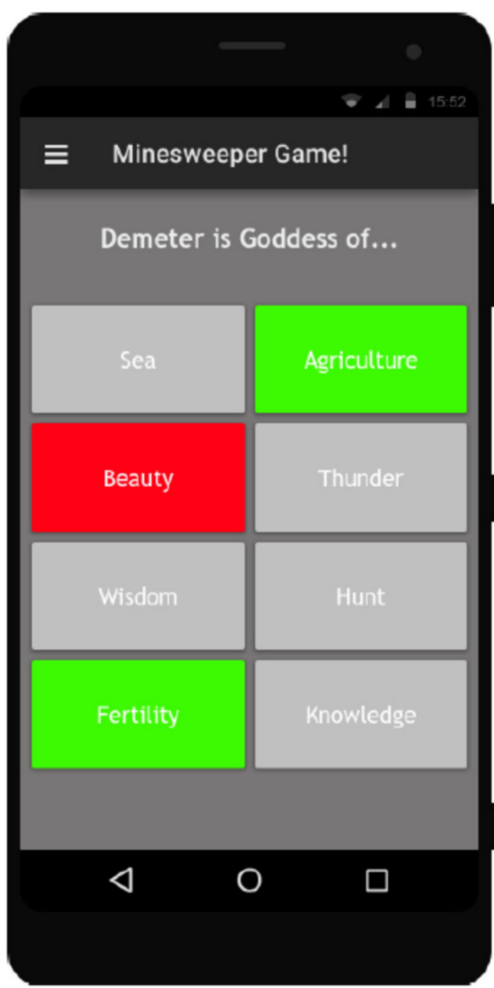

(c)

Figure 3. (a) Level of remembering (quiz game); (b) level of understanding (picture game); (c) level of applying (minesweeper game).

During the process of remembering, the learners should be able to recall, restate, or make use of the information they have learned. In our case, the first activity is a simple knowledge game, which aims to retrieve the knowledge acquired by students when studying the theory. More specifically, users can interact with a multi-query game environment, where students are asked to choose the correct answers and, at the end, all the questions and the answers are displayed in order, with the indication "right" or "wrong". As such, in this level, the skill of remembering can be improved since the students should recollect the theory.

In the understanding phase, it must be checked whether the student, in addition to simply memorizing words, concepts, and theories, is able to classify categories, distinguish similar objects, and find what is required, in order to finally lead to certain conclusions. Hence, at the level of understanding (Figure 3b), in the application, students can first see an image which is somewhat blurred. This image is related to a question on the same screen. The students should be able to distinguish the vague object and, by also using their previous knowledge, can record it in the specially designed field. In this way, they can further improve their skill of understanding.

At the level of applying (Figure 3c), a concept or generalization is used in new situations and contexts, therefore, applying knowledge from school to other areas. Students can solve a problem, use principles in real situations, and predict result. The third level in Bloom's classification requires both knowledge and understanding by the learner. At this level, the ability to use knowledge is examined; the knowledge that was not only memorized, but also understood, can serve as a tool for the student to solve requested situations. In view of the above, at this level, students are asked to utilize information that they have been provided to produce a practical solution to a problem.

The next activity is related to the levels of analyzing and evaluating (Figure 4). More specifically, students should be able to distinguish objects that are not included in a par- 
ticular image. Next, students are required to design them. In addition, at these levels, students can test their abilities to discern situations, intentions, and implications that are not listed, and often modify their original perceptions. In more detail, at the level of analyzing, students are asked to identify patterns to solve problems. They should distinguish between objective and subjective information in order to explore and draw conclusions using their point of view. At the level of evaluating, students should utilize particular facts to make predictions or produce new theories. This requires them to apply skills to synthesize this information before drawing conclusions.

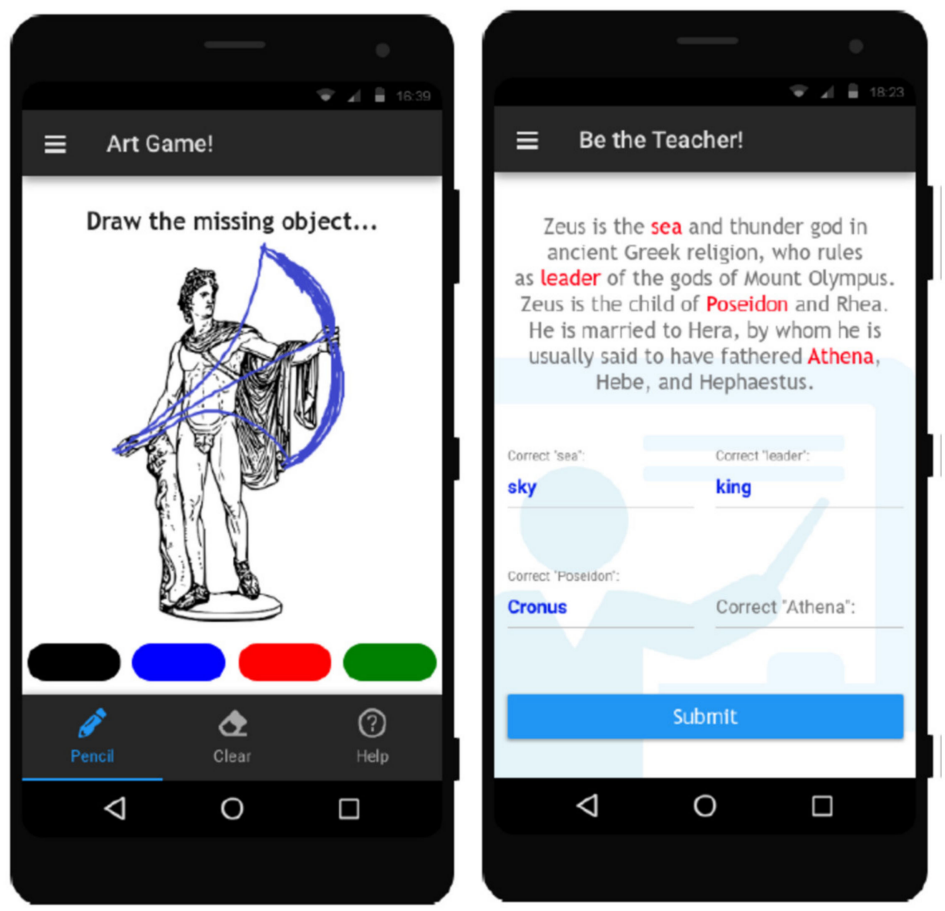

Figure 4. Levels of analyzing (art game) and evaluating (Be the Teacher! game).

Finally, students pass to the final level of creating. According to Bloom, at this level, a student is asked to put elements together in order to form a new coherent pattern or structure. Mobile learning software provides students with activities requiring them to know how to develop new knowledge and make special judgments.

\subsection{Motivational Feedback Delivery}

Malone and Lepper's motivation theory [22] was used for the design of the mobile learning software. This taxonomy divides the motivating factors of students' interests into four main categories: motivations that come from challenge, curiosity, control, and fantasy (Figure 5).

The taxonomy is described as follows:

- Motivation through challenge More specifically, this motivation concerns messages that are challenging for the student to advance their knowledge. By presenting only part of the information that is quite provocative, students are challenged to look for the remaining unknown concepts (Figure 6a). The motivational message shows part of the information, rendering students who are interested in learning more. The characteristics of this element involve goals, uncertain outcomes with different difficulty levels, and the ability to gain self-esteem and self-efficacy.

- Motivation through control The messages promote a sense of control towards the student, meaning that learning outcomes are determined by the student's actions (Figure 6b). Students receive additional information, take control, and decide whether 
they wants to learn more through a motivating interaction. The characteristics of this element involve a reactive learning environment, choice, and learners' power.

- Motivation through fantasy These motivations promise students a fantasy world, i.e., the "mental images" that the learners create based on their interaction with the environment (Figure 7a). The characteristics of this element involve an appeal to emotional needs and relationships to material that was previously learned.

- Motivation through curiosity According to Malone and Lepper, motivation through curiosity is achieved through various audiovisual media (Figure $7 \mathrm{~b}$ ). The characteristic of this element involves interactivity between learner and environment, which should intrigue the learner.

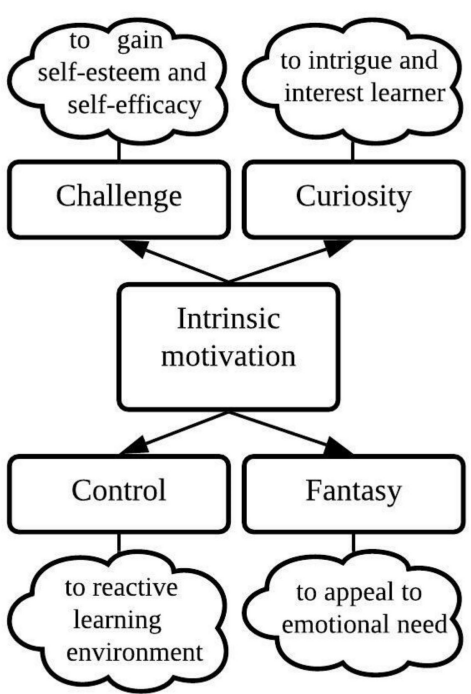

Figure 5. Malone and Leeper's taxonomy categories.

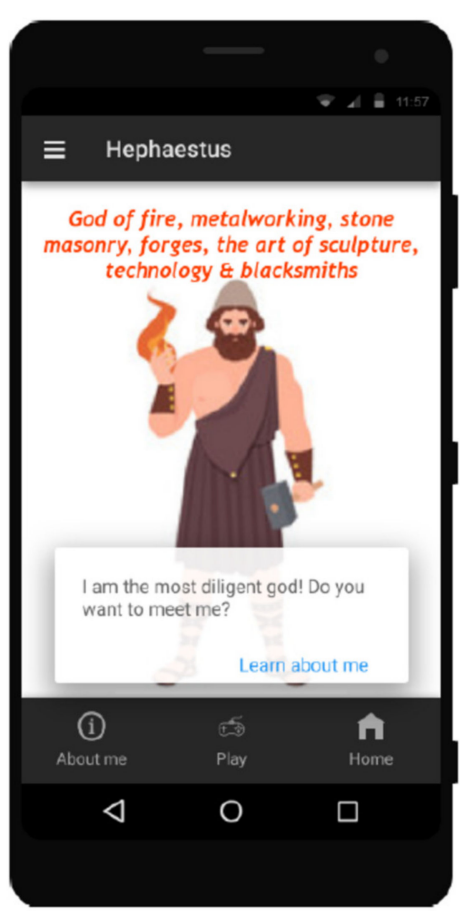

(a)

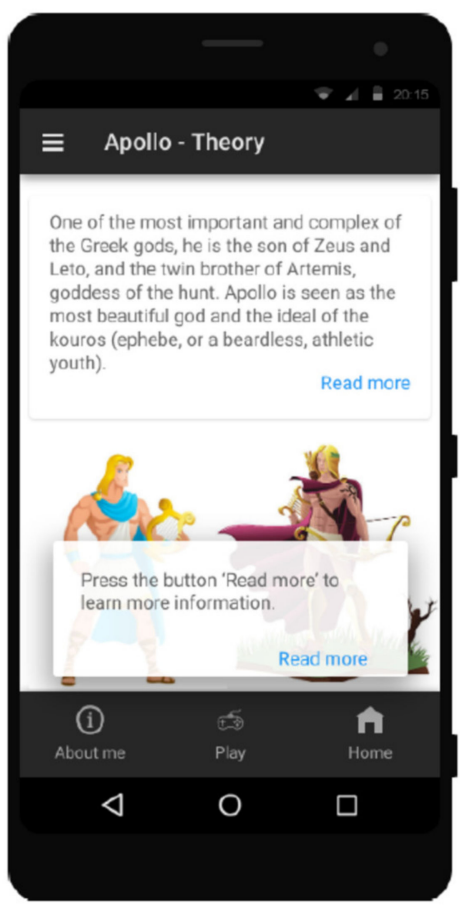

(b)

Figure 6. (a) Motivation through challenge; (b) motivation through control. 


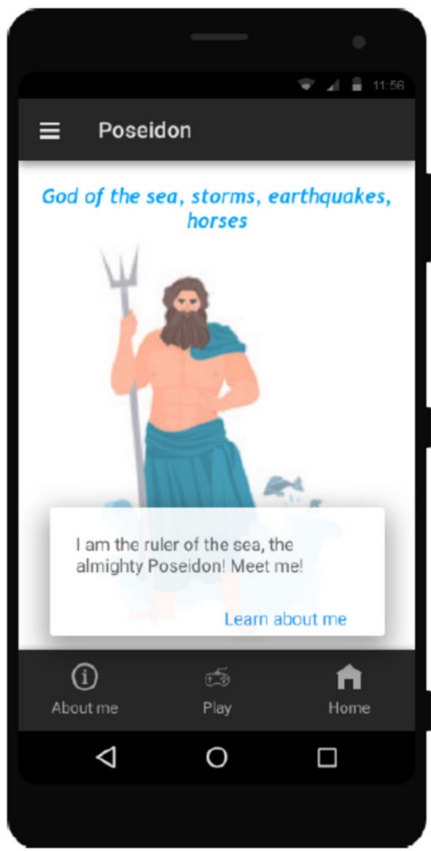

(a)

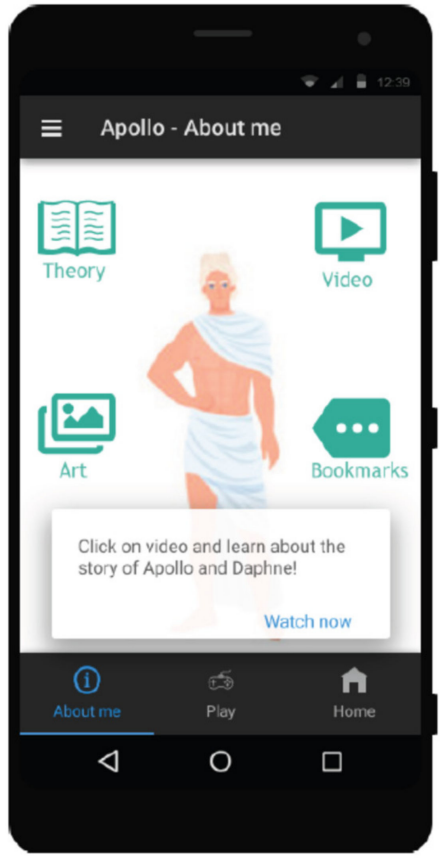

(b)

Figure 7. (a) Motivation through fantasy; (b) motivation through curiosity.

\section{Evaluation}

A user-based evaluation was conducted in order to assess the effectiveness and acceptance of the presented mobile learning software regarding the innovative interactive activities and motivational messages, which were incorporated. The aim of the evaluation was to assess the presented mobile learning approach, which merged Bloom's and Malone and Lepper's taxonomies. The mobile application was developed as a testbed for the mobile learning procedure.

\subsection{Methods and Materials}

The evaluation of the mobile learning application was based on four dimensions, namely the user experience, the effectiveness of interactive activities, the effectiveness of motivational feedback and the impact on learning [32]. The evaluation technique, which was used, included a 5-point Likert scale questionnaire survey delivered to the population after completion of the course. The questionnaire items were designed so that information about the user experience, the effectiveness of learning strategies adopted, and their impact on learning, could be gathered. Table 1 illustrates the questionnaire survey for the system evaluation. Furthermore, an interview method was used; the population was asked open-ended questions concerning the user friendliness and pleasantness of the system. In the interview process, two teachers of the students (population) helped the evaluators by conversing with respondents in order to collect and elicit data about the aforementioned subjects.

Table 1. System evaluation survey questions.

\begin{tabular}{ccc}
\hline Dimension & $\#$ & Questions \\
\hline & 1 & The interface of the system is pleasant. (1-5) \\
User experience & 2 & I am satisfied with how easy to use the system is. (1-5) \\
& 3 & I enjoy interacting with the system. (1-5) \\
\hline
\end{tabular}


Table 1. Cont.

\begin{tabular}{|c|c|c|}
\hline Dimension & $\#$ & Questions \\
\hline \multirow{3}{*}{ Effectiveness of interactive activities } & 4 & The activities are creative and innovative. (1-5) \\
\hline & 5 & The activities engage me in higher-order thinking. (1-5) \\
\hline & 6 & I am satisfied with the quality of the activities. (1-5) \\
\hline \multirow{3}{*}{$\begin{array}{l}\text { Effectiveness of motivational } \\
\text { feedback }\end{array}$} & 7 & The feedback helps me redefine my learning path. (1-5) \\
\hline & 8 & The motivational messages are insightful. (1-5) \\
\hline & 9 & My interest in the course is stimulated by the system. (1-5) \\
\hline \multirow{3}{*}{ Impact on learning } & 10 & The system helps me achieve higher-order cognitive skills. (1-5) \\
\hline & 11 & The feedback provided is effective in engaging me in the learning process. (1-5) \\
\hline & 12 & I believe the system helps me understand better lesson's concepts. (1-5) \\
\hline
\end{tabular}

\subsection{Evaluation Process and Population}

The population of the evaluation included 40 students at a Greek public primary school. Students' age, computer skills, and knowledge were approximately equal, as all of them were at the same grade. The students were separated into two groups of 20 members, namely Group 1 and Group 2. The experiment took place during the COVID-19 quarantine, when the school was closed and students were attending school remotely via Internet. As mentioned in Section 2, the lesson, which was taught using the mobile learning system, belonged to the "History" course, and the learning process had a duration of six didactic hours. The course is compulsory in primary schools. In addition, the goals of the instruction are for the students to: gain knowledge of historical facts as well as mythological figures; understand ancient society and develop a sense of the cultural heritage in current society; and develop new skills, such as enquiry, investigation, analysis, evaluation and presentation.

In particular, Group 1 was taught the section solely using the presented mobile learning software, incorporating interactive activities and motivational feedback; Group 2 used a conventional system, including mainly multiple-choice activities and simple motivational messages provided randomly to students. Using this conventional system in the evaluation process, the potential of designing mobile learning software according to learning theories, namely Bloom's taxonomy and Malone and Lepper's taxonomy, could be investigated. After completion of the section taught, the students were asked to answer the aforementioned questionnaire survey.

\subsection{Results and Discussion}

Regarding students' acceptance of the presented system, the answers given by Group 1 were assessed. Figure 8 and Table 2 illustrate the evaluation results. Analyzing these results, it is observed that there is a high rating of satisfaction and acceptance.

Considering user experience, $85 \%$ of the students found that the system interface was pleasant and stimulated them to use it further. Moreover, based on the interview results, almost all of the students stated that the system was very easy to use (95\%) and they enjoy interacting with it $(90 \%)$. These factors both play an important role in students' intention to use this system and in avoiding dropouts.

Regarding the effectiveness of the interactive activities incorporated into the system, $85 \%$ of the students found them creative and innovative, as well, an equally high percentage of them indicated their high quality $(90 \%)$. These results illustrate the acceptance of the proposed approach and the proper activities' design made during the system development phase. Furthermore, the vast majority of the participants (90\%) reported that the activities engaged them in higher order thinking skills, strengthening the choice of adopting Bloom's taxonomy in the activities' design. 


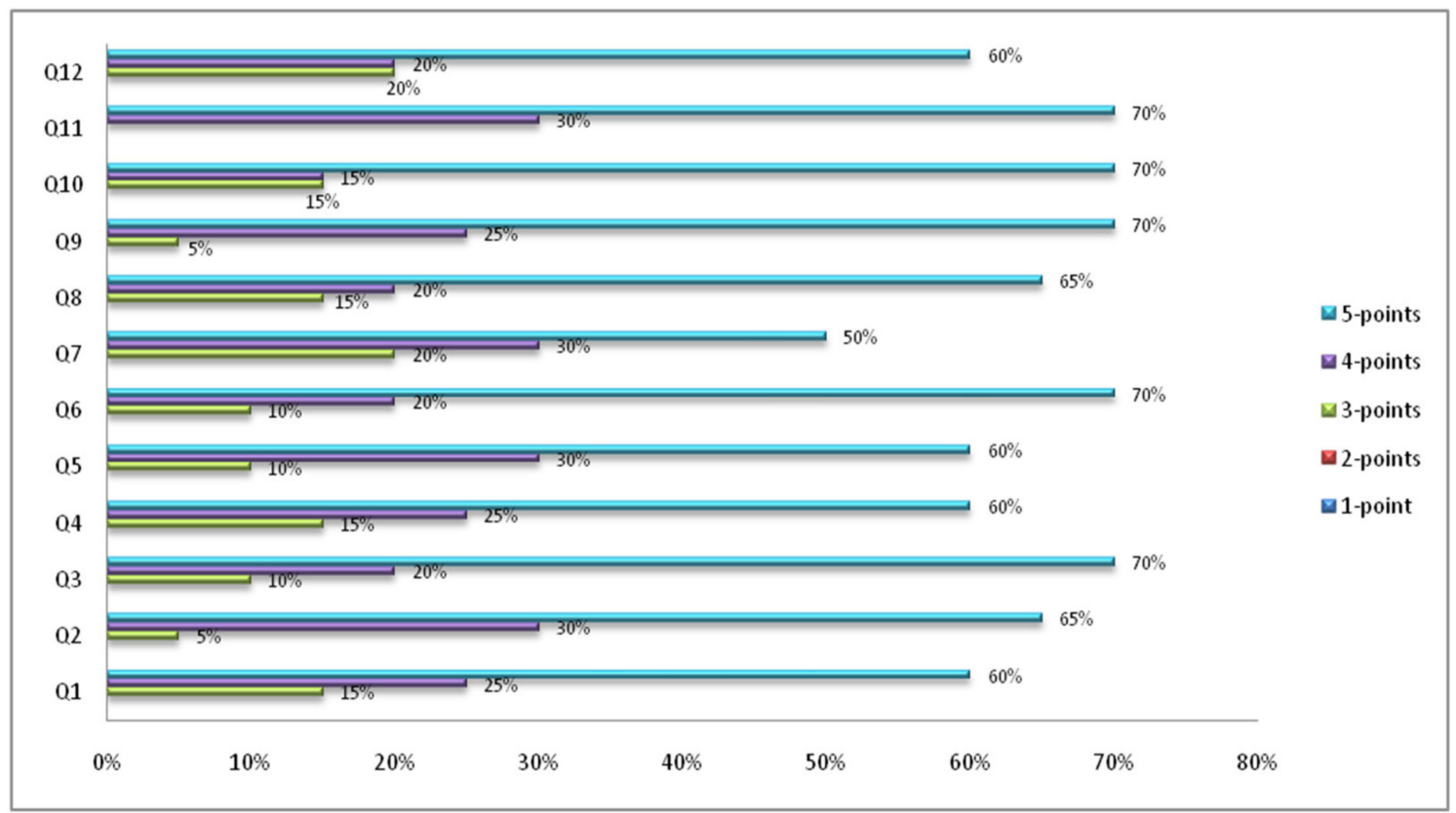

Figure 8. Bar chart for questionnaire survey results.

Table 2. Questionnaire survey results (scores, mean, standard deviation, and variance).

\begin{tabular}{|c|c|c|c|c|c|c|c|c|c|}
\hline & & 1-Point & 2-Points & 3-Points & 4-Points & 5-Points & Mean & $\begin{array}{c}\text { St. } \\
\text { Deviation }\end{array}$ & Variance \\
\hline \multirow{3}{*}{ User Experience } & Q1 & $0 \%$ & $0 \%$ & $15 \%$ & $25 \%$ & $60 \%$ & 4.45 & 0.7399 & 0.5475 \\
\hline & $\mathrm{Q} 2$ & $0 \%$ & $0 \%$ & $5 \%$ & $30 \%$ & $65 \%$ & 4.6 & 0.5831 & 0.34 \\
\hline & $\widehat{\mathrm{Q}} 3$ & $0 \%$ & $0 \%$ & $10 \%$ & $20 \%$ & $70 \%$ & 4.6 & 0.6633 & 0.44 \\
\hline \multirow{3}{*}{$\begin{array}{c}\text { Effectiveness of } \\
\text { interactive activities }\end{array}$} & Q4 & $0 \%$ & $0 \%$ & $15 \%$ & $25 \%$ & $60 \%$ & 4.45 & 0.7399 & 0.5475 \\
\hline & Q5 & $0 \%$ & $0 \%$ & $10 \%$ & $30 \%$ & $60 \%$ & 4.5 & 0.6708 & 0.45 \\
\hline & Q6 & $0 \%$ & $0 \%$ & $10 \%$ & $20 \%$ & $70 \%$ & 4.6 & 0.6633 & 0.44 \\
\hline \multirow{3}{*}{$\begin{array}{l}\text { Effectiveness of } \\
\text { motivational feedback }\end{array}$} & Q7 & $0 \%$ & $0 \%$ & $20 \%$ & $30 \%$ & $50 \%$ & 4.3 & 0.781 & 0.61 \\
\hline & $\mathrm{Q} 8$ & $0 \%$ & $0 \%$ & $15 \%$ & $20 \%$ & $65 \%$ & 4.5 & 0.7416 & 0.55 \\
\hline & Q9 & $0 \%$ & $0 \%$ & $5 \%$ & $25 \%$ & $70 \%$ & 4.65 & 0.5723 & 0.3275 \\
\hline \multirow{3}{*}{ Impact on Learning } & Q10 & $0 \%$ & $0 \%$ & $15 \%$ & $15 \%$ & $70 \%$ & 4.55 & 0.7399 & 0.5475 \\
\hline & Q11 & $0 \%$ & $0 \%$ & $0 \%$ & $30 \%$ & $70 \%$ & 4.7 & 0.4583 & 0.21 \\
\hline & Q12 & $0 \%$ & $0 \%$ & $20 \%$ & $20 \%$ & $60 \%$ & 4.4 & 0.8 & 0.64 \\
\hline
\end{tabular}

In view of the motivational feedback that was provided to students, the evaluation results show that it was found to be very useful to redefine their learning path $(80 \%)$, as well as the messages were very insightful $(85 \%)$. The system stimulated students' interests to a very high degree $(95 \%)$. These facts indicate the effectiveness of the motivational messages used and, by extension, the effectiveness of Malone and Lepper's taxonomy adopted for this purpose.

Regarding the impact of the presented system on learning, approximately $85 \%$ of the students stated that it helped them to achieve higher order thinking skills and to better understand the lesson's concepts. This high degree of rating in these questions can be explained by the use of Bloom's taxonomy which focuses on increasing knowledge and developing skills. In addition, $80 \%$ of the students reported that the feedback provided influenced their learning positively by engaging them in the educational process. A possible reason why this happened is because the messages were designed based on the principles of Malone and Lepper's taxonomy.

It needs to be noted that Values 1 and 2 received no responses. This fact was anticipated, since the younger generation is very keen on using smartphones and is acquainted with mobile applications. 
In order to further investigate the potential of the approaches used for activities and feedback as comparing with conventional ones, a two-sample $t$-Test between Group A and Group B was applied in the aggregation of Questions 4-6, which referred to the effectiveness of the interactive activities, and of Questions 7-9, which referred to the effectiveness of the motivational feedback. As shown in Table 3, there is a statistically significant difference between the means of the two groups regarding the two learning strategies. Considering the activities used in both systems, the presented system outperforms the conventional one, indicating that designing interactive activities based on a learning theory, such as Bloom's taxonomy, and not using simply multiple-choice activities can enhance learning and lead to the acquisition of higher order cognitive skills. Regarding the feedback to students, the findings show that the presented system which adopts the Malone and Lepper's taxonomy for designing the motivational messages outperforms the conventional one. As such, the adopted approach can be characterized as a suitable one which properly motivates the students to be more active and engages them into the learning process, helping them to improve their learning outcomes.

Table 3. $t$-Test results.

\begin{tabular}{|c|c|c|c|c|}
\hline & \multicolumn{2}{|c|}{ Effectiveness of Interactive Activities } & \multicolumn{2}{|c|}{ Effectiveness of Motivational Feedback } \\
\hline & Group A & Group B & Group A & Group B \\
\hline Mean & 4.65 & 3.2 & 4.45 & 3.15 \\
\hline Variance & 0.345 & 0.8 & 0.576 & 0.45 \\
\hline Observations & 20 & 20 & 20 & 20 \\
\hline Pooled variance & 0.572 & & 0.513 & \\
\hline Hypothesized mean difference & 0 & & 0 & \\
\hline $\mathrm{df}$ & 38 & & 38 & \\
\hline$t$ Stat & 6.06 & & 5.739 & \\
\hline $\mathrm{P}(\mathrm{T}<=t)$ two-tail & $4.7 \times 10^{-7}$ & & $1.3 \times 10^{-6}$ & \\
\hline$t$ Critical two-tail & 2.024 & & 2.024 & \\
\hline
\end{tabular}

\section{Conclusions and Future Work}

This paper presents a novel approach for delivering interactive learning activities and motivational feedback. To achieve this, Bloom's taxonomy and the taxonomy of intrinsic motivations by Malone and Lepper are utilized. In more detail, Bloom's taxonomy is used for the design of interactive activities belonging to varying levels of complexity, i.e., remembering, understanding, applying, analyzing, evaluating, and creating. Concerning the motivational feedback, the taxonomy of intrinsic motivations by Malone and Lepper is used, identifying four major factors, namely challenge, curiosity, control, and fantasy, rendering the learning environment intrinsically motivating. This approach has been incorporated in a mobile learning software for teaching a primary school course.

The mobile learning application were evaluated in a public primary school and the results showed that it could contribute positively to the advancement of learners' higher level cognitive skills. It needs to be noted that the presented approach can be incorporated in any mobile learning software, designed for learners of different grades and in different courses.

Based on the evaluation results, the significance of this study emerges from the incorporation of the two taxonomies in a mobile learning software, which can push the boundaries of virtual learning environments and further enhance online education by providing student-centered instruction.

Future research should include a more extensive evaluation in terms of the population. In addition, we plan to consider more learners' characteristics in the modeling process in terms of their types of misconceptions and emotional states. 


\begin{abstract}
Author Contributions: Conceptualization, C.T. and A.K.; methodology, C.T. and A.K.; software, C.T. and A.K.; validation, C.T. and A.K.; formal analysis, C.T. and A.K.; investigation, C.T. and A.K.; resources, C.T. and A.K.; data curation, C.T. and A.K.; writing-original draft preparation, C.T. and A.K.; writing-review and editing, C.T. and A.K.; visualization, C.T. and A.K.; supervision, C.S. All authors have read and agreed to the published version of the manuscript.
\end{abstract}

Funding: This research received no external funding.

Institutional Review Board Statement: Not applicable.

Informed Consent Statement: Not applicable.

Data Availability Statement: The data has been presented in main text.

Conflicts of Interest: The authors declare no conflict of interest.

\title{
References
}

1. Troussas, C.; Virvou, M.; Alepis, E. Comulang: Towards a collaborative e-learning system that supports student group modeling. SpringerPlus 2013, 2, 387. [CrossRef] [PubMed]

2. Rodríguez, M.E.; Guerrero-Roldán, A.-E.; Baneres, D.; Noguera, I. Students' Perceptions of and Behaviors toward Cheating in Online Education. IEEE J. Lat.-Am. Learn. Technol. 2021, 16, 134-142. [CrossRef]

3. Chrysafiadi, K.; Troussas, C.; Virvou, M. A Framework for Creating Automated Online Adaptive Tests Using Multiple-Criteria Decision Analysis. In Proceedings of the IEEE International Conference on Systems, Man, and Cybernetics (SMC), Miyazaki, Japan, 7-10 October 2018; pp. 226-231. [CrossRef]

4. Krouska, A.; Troussas, C.; Virvou, M. Social networks as a learning environment: Developed applications and comparative analysis. In Proceedings of the 8th International Conference on Information, Intelligence, Systems \& Applications (IISA), Larnaca, Cyprus, 27-30 August 2017; pp. 1-6. [CrossRef]

5. Moldovan, A.-N.; Muntean, C.H. DQAMLearn: Device and QoE-Aware Adaptive Multimedia Mobile Learning Framework. IEEE Trans. Broadcast. 2021, 67, 185-200. [CrossRef]

6. Li, X.; Heng, Q. Design of Mobile Learning Resources Based on New Blended Learning: A Case Study of Superstar Learning APP. In Proceedings of the IEEE 3rd International Conference on Computer Science and Educational Informatization (CSEI), Xinxiang, China, 18-20 June 2021; pp. 333-338. [CrossRef]

7. Wang, C.; Li, Q.; Hu, X. Minority college students' engagement in learning activities and its relationships with learning outcomes In Proceedings of the International Conference on Advanced Learning Technologies (ICALT), Tartu, Estonia, 12-15 July 2021; pp. 173-175. [CrossRef]

8. Simonova, I.; Faltynkova, L.; Kostolanyova, K. Learners' Motivation Types in the Smart Instruction of English for Specific Purposes. In Proceedings of the 6th IEEE Congress on Information Science and Technology (CiSt), Agadir-Essaouira, Morocco, 5-12 June 2021; pp. 225-230. [CrossRef]

9. Venditti, A.; Fasano, F.; Risi, M.; Tortora, G. The importance of interaction mechanisms in blended learning courses involving problem solving e-tivities. In Proceedings of the Thirteenth International Conference on Digital Information Management (ICDIM), Berlin, Germany, 24-26 September 2018; pp. 124-129. [CrossRef]

10. Troussas, C.; Krouska, A.; Sgouropoulou, C. A Novel Teaching Strategy Through Adaptive Learning Activities for Computer Programming. IEEE Trans. Educ. 2021, 64, 103-109. [CrossRef]

11. Weerasinghe, T.A. An Evaluation of Different Types of Blended Learning Activities in Higher Education. In Proceedings of the IEEE 18th International Conference on Advanced Learning Technologies (ICALT), Mumbai, India, 9-13 July 2018 ; pp. 42-45. [CrossRef]

12. Recke, M.P.; Perna, S.; Pereira, T.G. Designing Narratively Driven Learning Activities for Blended Learning Experiences. In Proceedings of the 9th International Conference on Information and Education Technology (ICIET), Okayama, Japan, 27-29 March 2021; pp. 171-177. [CrossRef]

13. Krouska, A.; Troussas, C.; Virvou, M. Computerized Adaptive Assessment Using Accumulative Learning Activities Based on Revised Bloom's Taxonomy. In Knowledge-Based Software Engineering: 2018, Proceedings of the JCKBSE 2018: Joint Conference on Knowledge-Based Software Engineering, Corfu, Greece, 27-30 August 2018; Virvou, M., Kumeno, F., Oikonomou, K., Eds.; Smart Innovation, Systems and Technologies; Springer: Cham, Switzerland, 2019; Volume 108.

14. Supic, H. Case-Based Reasoning Model for Personalized Learning Path Recommendation in Example-Based Learning Activities. In Proceedings of the IEEE 27th International Conference on Enabling Technologies: Infrastructure for Collaborative Enterprises (WETICE), Paris, France, 27-29 June 2018; pp. 175-178. [CrossRef]

15. Beardsley, M.; Gutierrez, N.; Hernandez-Leo, D. Examining university students' motivation, abilities and preferences related to learning to learn. In Proceedings of the IEEE 20th International Conference on Advanced Learning Technologies (ICALT), Tartu, Estonia, 6-9 July 2020; pp. 346-348. [CrossRef] 
16. Troussas, C.; Krouska, A.; Virvou, M. Using a Multi Module Model for Learning Analytics to Predict Learners' Cognitive States and Provide Tailored Learning Pathways and Assessment. In Machine Learning Paradigms; Virvou, M., Alepis, E., Tsihrintzis, G., Jain, L., Eds.; Intelligent Systems Reference Library; Springer: Cham, Switzerland, 2020; Volume 158.

17. Merzdorf, H.E.; Douglas, K.A. Surveying Motivation and Learning Outcomes of Advanced Learners in Online Engineering Graduate MOOCs. In Proceedings of the IEEE Frontiers in Education Conference (FIE), Uppsala, Sweden, 21-24 October 2020; pp. 1-4. [CrossRef]

18. Troussas, C.; Krouska, A.; Alepis, E.; Virvou, M. Intelligent and adaptive tutoring through a social network for higher education. New Rev. Hypermedia Multimed. 2020, 26, 138-167. [CrossRef]

19. D'Aniello, G.; De Falco, M.; Gaeta, M.; Lepore, M. A Situation-aware Learning System based on Fuzzy Cognitive Maps to increase Learner Motivation and Engagement. In Proceedings of the IEEE International Conference on Fuzzy Systems, Glasgow, UK, 19-24 July 2020; pp. 1-8. [CrossRef]

20. Virvou, M.; Troussas, C.; Caro, J.; Espinosa, K.J. User Modeling for Language Learning in Facebook. In Text, Speech and Dialogue, Proceedings of the TSD 2012: International Conference on Text, Speech and Dialogue, Brno, Czech Republic, 3-7 September 2012; Sojka, P., Horák, A., Kopeček, I., Pala, K., Eds.; Lecture Notes in Computer Science; Springer: Berlin/Heidelberg, Germany, 2012; Volume 7499.

21. Bloom, B.S. Taxonomy of Educational Objectives. In Handbook I: The Cognitive Domain; David McKay Co Inc.: New York, NY, USA, 1956.

22. Malone, T.W.; Lepper, M.R. Making Learning Fun: A Taxonomy of Intrinsic Motivations for Learning. In Aptitude, Learning, and Instruction: Conative and Affective Process Analyses; Snow, R., Farr, M.J., Eds.; Lawrence Erlbaum Associates Publishers: Hillsdale, NJ, USA, 1987.

23. Krouska, A.; Troussas, C.; Virvou, M. A Literature Review of Social Networking- Based Learning Systems Using a Novel ISO-based Framework. Intell. Decis. Technol. 2019, 13, 23-39. [CrossRef]

24. Stefaniak, J.; Xu, M. An Examination of the Systemic Reach of Instructional Design Models: A Systematic Review. TechTrends 2020, 64, 710-719. [CrossRef]

25. Kloos, C.D.; Alario-Hoyos, C. Educational Pyramids Aligned: Bloom's Taxonomy, the DigCompEdu Framework and Instructional Designs. In Proceedings of the IEEE World Engineering Education Forum/Global Engineering Deans Council (WEEF/GEDC), Madrid, Spain, 15-18 November 2021; pp. 110-117. [CrossRef]

26. Troussas, C.; Krouska, A.; Sgouropoulou, C. Improving Learner-Computer Interaction through Intelligent Learning Material Delivery Using Instructional Design Modeling. Entropy 2021, 23, 668. [CrossRef] [PubMed]

27. Kannan, V.; Gouripeddi, S.P. Enhancement in Critical Thinking Skills Using the Peer Instruction Methodology. In Proceedings of the IEEE 18th IEEE International Conference on Advanced Learning Technologies (ICALT), Mumbai, India, 9-13 July 2018; pp. 307-308. [CrossRef]

28. Venkatalakshmi, B.; Balakrishnan, R.; Saravanan, V.; Renold, A.P. Impact of simulation software as teaching tools in engineering learning-An instructional design choice. In Proceedings of the IEEE Global Engineering Education Conference (EDUCON), Abu Dhabi, United Arab Emirates, 10-13 April 2016; pp. 868-873. [CrossRef]

29. Troussas, C.; Krouska, A.; Virvou, M.; Sougela, E. Using Hierarchical Modeling of Thinking Skills to Lead Students to Higher Order Cognition and Enhance Social E-Learning. In Proceedings of the 9th International Conference on Information, Intelligence, Systems and Applications (IISA), Zakynthos, Greece, 23-25 July 2018; pp. 1-5. [CrossRef]

30. Nolen, S.B.; Koretsky, M.D. Affordances of Virtual and Physical Laboratory Projects for Instructional Design: Impacts on Student Engagement. IEEE Trans. Educ. 2018, 61, 226-233. [CrossRef]

31. Sun, Z.; Wang, K.; Li, Z.; Li, Z. Development of CDIO-Based SPOC Model in Facilitating Learning Instructional Design. In Proceedings of the IEEE International Joint Conference on Information, Media and Engineering (ICIME), Osaka, Japan, 12-14 December 2018; pp. 236-239. [CrossRef]

32. Alepis, E.; Troussas, C. M-learning programming platform: Evaluation in elementary schools. Informatica 2017, 41, 471-478. 